a relative humidity of $93 \%$ at a temperature of $34.5^{\circ} \mathrm{C}$. $\left(94^{\circ}\right.$ F.). At the ambient temperature and relative humidity of his experiment air contains $5.52 \mathrm{~g}$. of water vapour per cubic metre.

In the experiments described here the water-vapour content of the humidified oxygen was in the range of 7.95 to $22.74 \mathrm{~g}$./ cu. m. This is above the amount which Perwitzschky has shown will rise to almost saturation level at body temperature in the trachea. His experiments were carried out on healthy subjects and lasted five minutes each. It is possible that prolonged mouth-breathing would have led eventually to a lower relative humidity in the trachea.

There seem to have been no comparable experiments in patients. One is therefore obliged to consider the varying circumstances that affect patients, and to speculate on their influence on humidity in the airways and the state of the bronchi. The purpose of humidification of oxygen for inhalation is the reduction of its capacity to dry the mucosa of the airways and of the mucus lying thereon. What constitutes a desirable level of humidification depends on factors that vary from patient to patient. A high level of humidity is required in the following circumstances: sticky mucus, a weak cough, a partially obstructed nose, prolonged mouth-breathing, a tracheostomy, and the use of masks involving admixture with ambient air when the latter is excessively dry.

My experience of many cases of acute chest infection over a number of years suggests that cases of moderate severity receive adequate humidification by the Woulfe bottle method. The indications of inadequate humidification are a dry mouth, strings of sticky mucus in the fauces, a rattly but unproductive cough with an adequately expulsive blast, or the expectoration of small amounts of very tenacious mucus with undue effort. These signs are especially likely to occur in gravely ill patients whose infections are complicated by emphysema or asthma, and in whom the maximal expiratory flow-rate and expulsive blast are much reduced. Patients with acute chest infections who have undergone tracheostomy are in similar plight. These patients require inspired gases which are saturated at body temperature.

\section{Summary}

The method of humidifying oxygen by bubbling it through water in a Woulfe bottle has been criticized. This method was tested by bubbling oxygen at three flow-rates $(3,5$, and $81 . /$ min.) and at three ambient temperatures (approximately $12^{\circ}$, $20^{\circ}$, and $32^{\circ}$ C.). The relative humidities ranged from 60 to $82 \%$, and water-vapour concentrations from 7.95 to $22.74 \mathrm{~g} . /$ cu. m. During the first few minutes of bubbling, before appreciable cooling had occurred in the water in the Woulfe bottle, the humidities were still higher. It is thought that humidification of oxygen by this method is adequate for the treatment of most chest infections and for non-respiratory disorders requiring oxygen.

Attention is again drawn to the fallacy of accepting relative humidity alone as a measure of the humidification of gases for inhalation. The need to use measurements of water-vapour concentrations for this purpose is emphasized.

A family of curves has been drawn to facilitate calculation of water-vapour concentration when the relative humidity and temperature are known.

I wish to thank Mr. C. Hinkel, of the Meteorological Office, for advice, and the South-east Metropolitan Regional Hospital Board and King's College Hospital for the grant of equipment and technical assistance.

Brit. med. F., 1964, 2, 1580.

REFERENCES

Cadman, E. F. B. (1961). Brit. med. 7., 1, 591

Hygrometric Tables, Meteorological Office, MO.265, 4th ed., 1940 (reprinted 1956). Appendix IIIB, p. 44.

Perwitzschky, R. (1927). Arch. Ohr.-, Nas.-, u. Kehlk.-Heilk., 117, 1.

Pugh, J., and Ward, M. (1953) The Ascent of Everest, by J. Hunt p. 278. London.

Ward, M. (1953). "The Medical Aspects of Mountaineering." Report on R.C.P. meeting, p. 14.

\title{
Heparin as an Analgesic in Myocardial Infarction: A Double-blind Trial
}

\author{
C. J. BULPITT,* M.B., M.R.C.P.
}

Brit. med. F., 1967, 3, 279-281

Nichol et al. (1959) reported that heparin usually relieves anginal pain, but no controls were employed. This impression has been repeated (British Medical fournal, 1966) but never proved. Heparin does not increase forearm blood flow (Lambert, 1958) and there is no evidence of a vasodilator effect. It was decided, therefore, to perform a double-blind study on the effects of intravenous heparin on myocardial pain, blood pressure, pulse rate, and electrocardiographic tracings. Twenty-eight patients with " myocardial infarction" took part in the trial.

\section{Method}

The patients had been admitted to a general medical ward, usually in the Medway Hospital. To enter the trial a patient had to satisfy the following criteria: he should have cardiac ischaemic pain but not show more than slight distress; he should not have received an anticoagulant within the preceding

* Medical Registrar, Medway Hospital, Gillingham, Kent. Present address: Whipps Cross Hospital, London few days, nor an opiate or drug of similar analgesic potency within the preceding six hours.

When the patient was first seen by a doctor a quick assessment was made. If the patient was not unduly distressed, and it was thought that no analgesic therapy would be required for 30 minutes, he was requested to enter the trial. He was told that he would receive an intravenous injection of a wellknown drug, to discover whether or not it would relieve his pain. One patient who showed distress during this trial was given morphine and withdrawn.

Each patient verbally answered the first of three questionaries. An intravenous injection of either $2 \mathrm{ml}$. of normal saline or $2 \mathrm{ml}$. of a solution containing 10,000 units of heparin was then given. The solutions, which were identical in appearance, were prepared in numbered phials and used in numerical order. The code was held by the pharmacist; who had randomly allocated the solutions.

The blood pressure and pulse rate were recorded, and nine patients had an electrocardiogram taken before and after the 
The Questionary

QUESTIONARY 1 (0 MINUTES) Please tick $(v)$ or cross $($ ) to indicate

Time. whether question is correct or incorrect.

1. Is the pain severe, moderate mild, or has it disappeared?

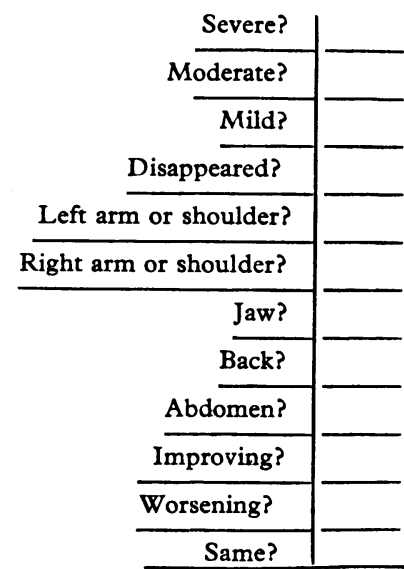

$$
\begin{aligned}
& \text { Pulse /min } \\
& \text { B.P. G. done/not done }
\end{aligned}
$$

* 10 minutes in Questionary 2 and 20 minutes in Questionary 3.

trial. After 10 and 30 minutes an identical questionary was answered and the blood pressure and pulse were again recorded.

The questionaries were devised to calculate the degree of pain present and thereby to assess any improvement. A points system provided a numerical basis. Severe pain rated six points, moderate pain four points, mild pain two points, and a "disappeared" pain counted nil. "Improving" counted minus two points, "worsening" plus two points, and "the same" counted nil. A radiating pain is probably more severe than one confined to the anterior chest wall, and plus one point was given for every site of radiation.

\section{Results}

Tables I and II show the patients' initial pain score and subsequent improvement or deterioration. The improvement is calculated from the difference between two pain ratings, a positive sign indicating a fall in pain rating and therefore improvement. Also shown are changes in pulse rate and diastolic blood pressure.

The 28 patients investigated had the characteristic pain plus typical electrocardiographic changes (Table I). Twenty-three of them had significantly raised transaminase levels. The patients were divided into two groups. The first group received heparin and the second saline. The heparin group included 12 men and three women, with an average age of 55 years. Two patients subsequently died during that hospital admission. The saline group included 12 men and one woman, with an average age of 58 years; three subsequently died. The only disparity between the groups is that the saline group showed higher transaminase levels. The mean aspartate aminotransferase level of the heparin group was 72 units and that of the saline group 103 units. The mean lactic dehydrogenase of the heparin group was 740 units and of the saline group 1,030 units.

Both groups showed pain relief 10 minutes after the injection. The difference between the two means is not significant $(P>0.5)$. There was no further reduction in pain between 10 and 30 minutes in either group. The analgesic effect of intravenous heparin in myocardial infarction was no greater than that of normal saline.

The changes in pulse rate are of interest. At 10 minutes there was a reduction in rate in the saline group. As indicated in Table I, one patient (Case 35) had atrial fibrillation. The reduction in radial pulse rate was possibly due to the fall in diastolic blood pressure of $20 \mathrm{~mm}$. $\mathrm{Hg}$, the vertex rate not necessarily being altered to such an extent. This finding was included in calculations, and the results are still not significant. $(\mathrm{P}>0.1)$.

Between 10 and 30 minutes there was a reduction in pulse rate only in the heparin group. This remains unexplained and is probably not significant $(P>0.05)$. The changes in diastolic blood pressure were minimal in both groups.

The six patients with "coronary insufficiency" had the characteristic prolonged pain at rest without typical electrocardiographic changes or marked elevation of the transaminase levels. The results in this section follow the pattern found in myocardial infarction (Table II). There is a similar degree of pain relief at 10 minutes and minimal improvement thereafter. Again heparin shows no advantage over saline in these patients.

Nine patients had an electrocardiographic tracing taken before the injection and after 30 minutes. Six had received heparin and three saline. Six patients showed no change in their electrocardiographic tracings. A minor increase in ischaemic change was observed in one patient receiving saline and in one receiving heparin. One patient receiving heparin showed a minor improvement in his tracing: an ST elevation of $1 \mathrm{~mm}$. in lead II reverted to the isoelectric line at 30

\begin{tabular}{|c|c|c|c|c|c|c|c|}
\hline \multirow{2}{*}{$\begin{array}{l}\text { Case } \\
\text { No. }\end{array}$} & \multirow{2}{*}{$\begin{array}{c}\text { Initial } \\
\text { Pain } \\
\text { Assess- } \\
\text { ment }\end{array}$} & \multicolumn{2}{|c|}{$\begin{array}{l}\text { Numerical } \\
\text { Improvement }\end{array}$} & \multicolumn{2}{|c|}{$\begin{array}{l}\text { Pulse Change } \\
\text { Beats/minute }\end{array}$} & \multicolumn{2}{|c|}{$\begin{array}{l}\text { Change in } \\
\text { Diastolic B.P. } \\
\text { in } \mathrm{mm} . \mathrm{Hg}\end{array}$} \\
\hline & & $\begin{array}{c}\text { At } \\
10 \\
\text { Mins. }\end{array}$ & $\begin{array}{l}\text { Between } \\
10 \text { and } \\
30 \text { Mins. }\end{array}$ & $\begin{array}{c}\text { At } \\
10 \\
\text { Mins. }\end{array}$ & $\begin{array}{c}\text { Between } \\
10 \text { and } \\
30 \text { Mins. }\end{array}$ & $\begin{array}{c}\text { At } \\
10 \\
\text { Mins. }\end{array}$ & $\begin{array}{c}\text { Between } \\
10 \text { and } \\
30 \text { Mins. }\end{array}$ \\
\hline
\end{tabular}
minutes.

\begin{tabular}{r|l|r|r|r|r|r|r|r}
\hline 4 & 4 & +1 & +3 & -2 & +1 & +16 & +8 \\
8 & 5 & +5 & 0 & 0 & -1 & -10 & 0 \\
8 & 7 & +2 & -4 & +12 & -8 & 0 & 0 \\
14 & 1 & 0 & +2 & -16 & -4 & +10 & 0 \\
20 & 3 & +1 & 0 & -2 & 0 & 0 & 0 \\
22 & 6 & +2 & +1 & -12 & +4 & +5 & +5 \\
23 & 1 & 0 & +6 & -4 & -6 & -5 & +15 \\
28 & 2 & +1 & -2 & +4 & -13 & +20 & -20 \\
30 & 6 & +4 & -2 & -12 & -16 & 0 & -20 \\
31 & 8 & +2 & -4 & +20 & -20 & -10 & 0 \\
33 & 9 & +8 & 0 & 0 & -8 & -5 & 0 \\
37 & 4 & +4 & +2 & +8 & -8 & -5 & -5 \\
41 & 7 & +4 & -2 & +6 & -2 & -3 & -2 \\
81 & 3 & +4 & -1 & 0 & 0 & - & - \\
\hline Mean & $4 \cdot 5$ & $2 \cdot 3$ & 0 & 0 & -5 & +1 & -1 \\
\hline
\end{tabular}
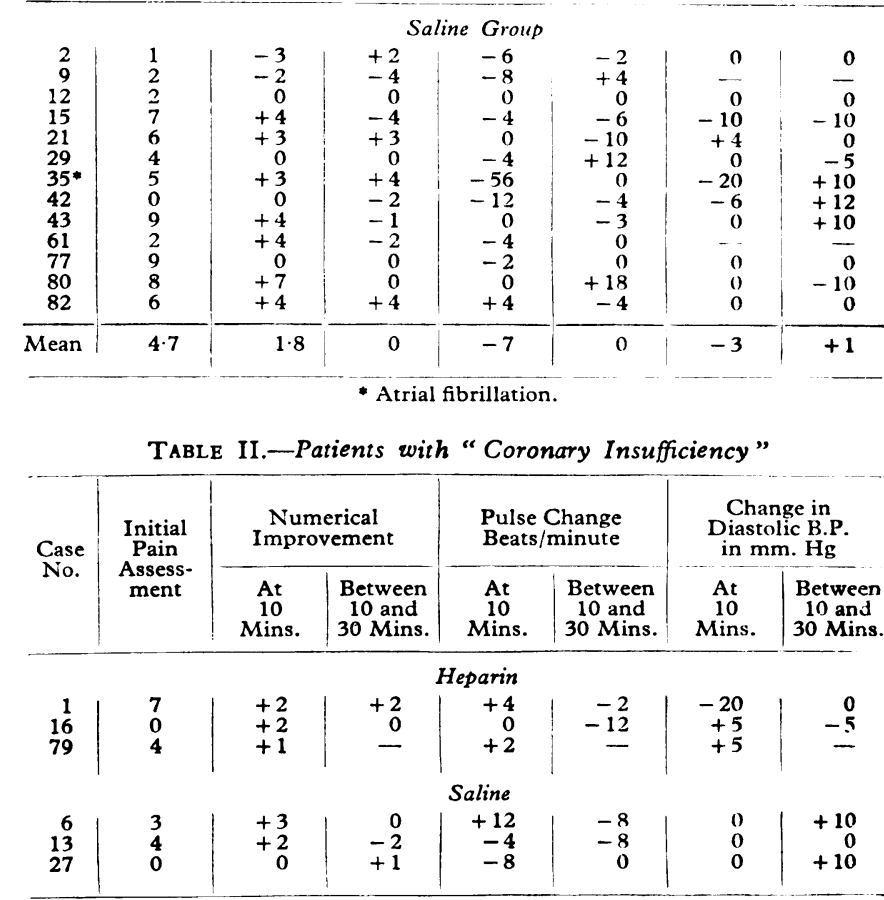


\section{Conclusions}

Under the conditions of this trial heparin did not exert an analgesic effect in myocardial infarction greater than that of a placebo, nor did it affect the pulse rate or diastolic blood pressure. There was no significant alteration in the electrocardiographic tracings of six patients who received heparin.

\section{Summary}

A double-blind trial was performed to determine the effect of intravenous heparin on myocardial pain, pulse rate, diastolic blood pressure, and the electrocardiographic tracing.
No significant differences were found from the placebo effects of intravenous saline.

I am indebted to Drs. F. A. Richards, R. A. Moir, J. D. Craig, and $M$. Sadiq for encouragement, criticism, and permission to study patients under their care. The chief pharmacist, Mr. H. Duckett, kindly prepared the drugs and held the code. My thanks are also due to the resident medical staff for their assistance and to Miss D. Rose for secretarial work.

REFERENCES

Brit. med. 7., 1966, 2, 3

Lambert, H. P. (1958). Clin. Sci., 17, 621

Nichol, E. S., Phillips, W. C., and Casten, G. G. (1959). Ann. intern. Med., 50, 1158

\title{
Calcium Infusion Test in Osteomalacia : an Appraisal
}

\author{
J. V. LEVER,* M.B., в.SC. ; C. R. PATERSON,* M.A., в.M., в.SC. ; D. B. MORGAN, $\dagger$ M.B.
}

Brit. med. F., 1967, 3, 281-282

Nordin and Fraser (1956), as well as many other authors, have reported that patients with osteomalacia retain more of an infused dose of calcium than normal persons. A high retention of infused calcium by itself has been taken as diagnostic of osteomalacia (Harvald et al., 1962; Deller et al., 1963; Thompson et al., 1966). Nordin and Fraser suggested that the calcium retained in osteomalacia was taken up by the uncalcified bone matrix-that is, osteoid tissue. If this was so then the amount of calcium retained should be related to the amount of osteoid.

We report here the relation between calcium retention and the amount of osteoid in trabecular bone in 15 patients.

\section{Patients}

Eleven patients had had a partial gastrectomy, but only four had typical osteomalacia with bone pains and a large increase in serum alkaline phosphatase which responded to vitamin $D$ (Morgan et al., 1965). The other seven were investigated because at that time we thought that a small increase in serum alkaline phosphatase, which they were shown to have, meant that they had a symptomless osteomalacia. Four further patients had typical osteomalacia which was not the result of gastric surgery. Three of these had proved gluten-induced enteropathy; the fourth is still being investigated.

\section{Methods}

The protocol for the infusion of calcium was that given by Nordin and Fraser (1956) except that calcium gluconate was infused in a $5 \%$ solution of dextrose and not in saline. Calcium in the urine was estimated by flame photometry (MacIntyre, 1961).

The proportion of the dose excreted was calculated from the difference between the calcium excreted in the urine in the 12 hours from the beginning of the infusion and the calcium excreted during the corresponding period on the previous day. The results were expressed as the percentage of the infused calcium retained in the body in the 12 hours.

* Research Assistant, Clinical Investigation Unit, University of Leeds. t Lecturer, Clinical Investigation Unit, University of Leeds.
The bone biopsy specimens were obtained from the iliac crest under local anaesthesia (Williams and Nicholson, 1963). The specimens were fixed in barbitone-buffered formalin (Ball, 1957) and sections cut without decalcification by Russell's (1956) technique. The area of osteoid in the section was expressed as a percentage of the total area of bone in the section. These measurements were made by Dr. C. G. Woods and will be reported by him elsewhere.

\section{Results and Discussion}

Fig. 1 shows that while all eight patients with typical osteomalacia retained most of the infused calcium so did four of the seven patients without an excess of osteoid in the bone. There was no relation between the amount of calcium retained and the area of osteoid.

Thus an excessive retention of calcium does not depend on an excess of osteoid. A similar conclusion could be drawn from the data of Thompson et al. (1966) and of Deller et al. (1963). The results in these two series have been plotted in Fig. 2, which includes our results for comparison. The histological criteria for the diagnosis of osteomalacia have been those of the respective authors.

The high retention of calcium in patients without osteoid is not limited to patients who have had a gastrectomy. Lindahl (1959) reported that a third of 70 patients with senile osteoporosis retained excessive amounts of infused calcium, though none of them had histological evidence of osteomalacia. Atkinson et al. (1956) reported an increased calcium retention in 7 out of 14 patients with chronic jaundice. Three of these seven had no osteoid on bone biopsy.

Apart from osteomalacia, high retention of calcium has been reported in other disorders of bone where osteoid is found. Thompson et al. reported, and we have confirmed, that in Paget's disease of bone there is an increased calcium retention after calcium infusion. Nordin and Fraser (1956) showed this in hypoparathyroidism, and also in a number of other diseases such as diabetes, rheumatoid arthritis, and renal failure.

The interpretation of calcium infusion tests may be questioned because normal persons retain as much as $73 \%$ of an infused dose, yet the retention of a further $10 \%$ is regarded as highly abnormal. The fate of the retained calcium is not 